\title{
PROPERTIES OF AFTERSHOCK SEQUENCES
}

R. D. Adams

Seismological Observatory, Geophysics Division, D.S.I.R. Wellington

Following the Inangahua earthquakes of May, 1968, the Seismological Observatory received many requests for information about aftershocks, and it became apparent that even among engineers and scientists in other. fields there was considerable. lack of knowledge of what to expect during an aftershock sequence. The following notes were therefore prepared, covering some of the points about which enquiries are most often recelved.

Earthquake sequences fall into several types. Swarms, such as the Taupo-Wairakei swarm of 1964, have no well-defined main shock and may continue for several months or, as in the case of the Matsushiro swarm in Japan, for several years. The positions of the earthquakes may migrate during the course of the swarm, and the frequency of occurrence of shocks rise to several local maxima before the swarm dies out. Eiby (1966) has discussed swarms in New Zealand and shown that they have occurred only in areas of Quaternary volcanism. Usually, these swarms are unaccompanied by volcanic manifestations, even when they occur in active volcanic regions, but they can herald an eruption as at Raoul Island in 1964, when 10 days of earthquake activity preceded a steam and mud emption (Adams and Dibble, 1967)。

Aftershock sequences generally follow large magnitude shallow earthquakes. Following the larger events, there is little doubt as to what constitutes an aftershock, but following smaller earthquakes it is necessary to set up criteria of spatial and time separation to discriminate between aftershocks and the normal earthquake activity of the area. I know of no earthquake in the New Zealand region definitely originating beneath the Mohorovicic discontinuity which has been followed by an aftershock sequence.

\section{Magnitude of aftershocks}

Following shallow earthquakes, it is often found that the magnitude of the largest aftershock is about 1.2 units less than that of the main shock. This purely empirical relationship is known as "Bath's Law". Examples of the magnitude difference between the main shock and largest aftershock for some recent New zealand sequences are: -

\begin{tabular}{lcccc}
\multicolumn{4}{c}{ Magnitude } \\
Sequence & Main Shock & $\begin{array}{c}\text { Largest } \\
\text { Aftershock }\end{array}$ & Difference \\
Fiordand 1960 & 7.0 & & 5.6 & 1.4 \\
Westport 1962 & 5.9 & 5.6 & 0.3 \\
Gisborne 1966 & 6.2 & 5.0 & 1.2 \\
Sedden & 1966 & 6.1 & 4.1 & 2.0 \\
Inangahua 1968 & 7.0 & 5.9 & 1.1
\end{tabular}


It is most unusual for the magnitude of an aftershock to approach that of the min shock, as in the Westport sequence. These shocks, one week apart, may possibly be regarded more as twin events rather than main shock and aftershock. There have been suggestions (Utsu, 1961) that this magnitude difference is a function of the magnitude of the main shock, with larger magnitude earthquakes being associated with smaller magnitude decrease to the largest aftershock. Utsu's relationship, which is not well established, is: -

$$
M_{0}-M_{1}=4.7-0.45 M_{O}
$$

where $\mathrm{M}_{0}$ and $\mathrm{M}$, are the magnitudes of the main shock and largest aftershock respectively. This relationship agrees with Bath's Law for $\mathrm{M}_{O}=7 \frac{3}{4}$.

The magnitude-frequency relationship for aftershock sequences is similar to that of other groups of earthquakes, and is of the form

$$
\log n(m)=a-b m
$$

where $n(m)$ is the number of earthquakes of magnitude greater or equal to m. For a particular sequence $a$ and $b$ are constants, and b generally has a value close to unity, implying that for each decrease of one unit in magnitude the number af aftershocks will increase by about a factor of 10, or conversely, for each 10 aftershocks of a given magnitude one can be expected of one magnitude higher.

It has been suggested that the magnitude of aftershocks decreases in the course of a sequence. This is now thought to be not so. Hamilton (1967) demonstrated that for the Gisborne aftershocks of 1966, the mean magnitude of consecutive groups of shocks did not alter during the sequence. As will be shown in the next section, however, the frequency of earthquakes of any given magnitude should decrease during the sequence.

\section{Frequency of occurrence}

The frequency of aftershocks per unit time interval $n(t)$ decreases with increasing time $t$ as given by the modified formula of omori

$$
n(t)=\frac{A}{(t+c)^{p}}
$$

where $A, c$, and $p$ are constants for a particular sequence. $c$ is usually less than a day, and $p$ somewhat greater than 1. (Utsu gives 1.3 as a typical value.) Values found for local sequences are: -

$\begin{array}{lcc} & c \text { (days) } & \underline{p} \\ \text { Fiordland, } 1960 & 0.10 & 1.12 \\ \text { Gisborne, } 1966 & 0.22 & 1.47\end{array}$

As a first approximation, the frequency of earthquakes is inversely proportional to the time since the main shock. Thus, 10 days after the main shock, the frequency of aftershocks should be about $1 / 10$ of that on the first day, and 100 days after the main shock, 1/100.

Nesting of aftershocks can occur, in which larger aftershocks are followed by an increase of smaller shocks. These will cause irregularities in the smooth decay pattern described above. 


\section{Areal extent of aftershocks}

Aftershocks of large magnitude earthquakes can cover a considerable area. Following the Alaskan earthquake of 1964 (magnitude $8 \frac{1}{2}$ ), aftershocks of magnitude 6 or more occurred over an area comparable in size and shape with the South Island of New Zealand. Utsu suggests the formula

$$
\log D=0.5 \mathrm{M}-1.8
$$

where $D$ is the linear dimension of the aftershock area in kilometres, following an earthquake of magnitude $M$. Typical values given by this formula are: -

$\begin{array}{lrl}M & D \\ 8 \frac{1}{2} & 280 \mathrm{~km} \\ 8 & 160 \mathrm{~km} \\ 7 & 50 \mathrm{~km} \\ 6 & 16 \mathrm{~km}\end{array}$

Epicentres of a sample of the largest aftershocks of the Inangahua $(M=7)$ shock cover an area of about $45 \times 25 \mathrm{~km}$, in good agreement with this relationship. Hamilton (1966), however, found that the larger aftershocks of the Fiordland earthquake of 1960 , also of magnitude 7 , were no more than $15 \mathrm{~km}$ from the epicentre of the main shock.

The extent of the aftershocks could make it possible for areas away from the centre of energy release of the main shock to be shaken at an intensity comparable with that of the main shock by a large aftershock originating at a closer distance.

\section{Summary}

It would be most unusual for an aftershock to approach the magnitude of the main shock.

The frequency of aftershocks should decrease at a rate that is to a first approximation inversely proportional to the time elapsed since the main shock.

Large magnitude aftershocks can occur at any time during the sequence, but naturally, the frequency of large shocks decreases with time.

\section{References}

ADAMS R.D. and DIBBIE R.R., 1967: Seismological Studies of the Raoul Island Eruption, 1964. N.Z. JI. Geol. Geophys. 10, 1348-61.

EIBY, G.A., 1966: Earthquake Swarms and Volcanism in New Zealand. Bull. Vol. 29, 61-73.

HAMIITON, R.M., 1966: The Fiordland Earthquake Sequence of 1960, and Seismic Velocities Beneath New Zealand. N.Z. JI. Geol. Geophys. 9, $224-38$.

HAMIITON, R.M., 1967: Mean Magnitude of an Earthquake Sequence. Bull. Seismol. Soc. Amer. 57, 1115-6.

UTSU, T., 1961: A Statistical Study on the Occurrence of Aftershocks. Geophys. Mag. 30, 521-605. 